\title{
Literacy of Autism Spectrum Disorder (ASD) among Clinical Year Medical Students in Malaysia
}

\author{
Article by Roy Rillera Marzo ${ }^{1}$, Samantha Wong LiySyen², Sylvia Sutharsana ${ }^{2}$ \\ ${ }^{1}$ Deputy Dean, Master in Public Health, Fellow in Public Health \\ ${ }^{2}$ Faculty of Medicine, Masterskill University College of Health Sciences \\ Email: rrmtexas@yahoo.com
}

\begin{abstract}
Objective: This study was carried out to assess the literacy of Autism Spectrum Disorder among clinical year medical student in Malaysia.

Methodology: This was a quantitative approach study in which the data was assessed cross-sectional and descriptively. The target population of this study was clinical year medical students from private and public universities. The data was collected through the method of multi-stage sampling which includes cluster and simple random sampling.

Results: Of the 210 clinical year medical students that responded to our study, 70(33.3\%) were males and 140(66.7\%) were females. There were more students from private universities 179(85.2\%) compared to public universities 31(14.8\%). The total mean score on belief about autism was $3.84 \pm 1.36$ out of the maximum 7. There were only 6 (2.9\%) out of 210 students who considered to have no misconception on ASD. The total mean score on knowledge was $12.93 \pm 3.56$ out of 19 . It was reported that only 3 (1.4\%) students out of 210 considered to have adequate knowledge. The findings in this study showed that there was lack of appropriate attitude of the clinical year medical students towards autistic individuals.

Conclusion: The recognition of the clinical year medical students in Malaysia regarding ASD is low as we can see that there are only $2.9 \%$ of the students have accurate belief and $1.4 \%$ of students have adequate knowledge about ASD. There are $85.7 \%$ of the students who see the autistic individual as normal individual, which to say that there are still presence of $14.3 \%$ who see them as abnormal. Thus, this shows that there are still certain level of stigmatization or discrimination which occurred. Belief and attitudes toward autistics can be improved in such a way that medical students would be exemplary to the public on the way autistics should be treated. Ignorance is due to the lack of knowledge thus, medical students should be equipped to educate the public regarding autism to eliminate the existing ignorance that can be seen in the public's attitude towards autism.
\end{abstract}

Keywords: Autism Spectrum Disorder, Medical Students, Knowledge, Belief, Attitude.

\section{Introduction}

The word autism originated from the Greek word "autos" which means "self". The term describes status in which a specific person is removed from social interaction hence, an isolated self. Eugen Bleular, a Swiss psychiatrist, first produced the word to define the symptoms of schizophrenia back in 1911. Eventually the term "autism" was used to describe children with emotional or social problems in the 1940s. A doctor, Leo Kanner from Johns Hopkins University described autism as developmental disease which is present from birth and withdrawn behaviour of several children he studied. Meanwhile, a scientist in Germany, Hans Asperger identified a similar condition that is now called Asperger's Syndrome.

So what is Autism anyways? Autism is more suitable to be known as Autism Spectrum Disorder (ASD) as it describes a range of complex neurodevelopmental conditions. This disorder is characterized by impaired social interaction, verbal and non-verbal communication, restricted interest and repetitive behaviour. In the 2013 fifth edition of the Diagnostic and Statistical Manual of Mental Disorder (DSM-5), the diagnosis of ASD which several disorders were previously diagnosed distinctly were combined into one umbrella 
South American Journal of Medicine

Volume 4, Issue 1, 2016

diagnosis of ASD. The disorders are comprised of autistic disorder, pervasive developmental disorder-not otherwise specified (PDD-NOS), childhood disintegrative disorder and Asperger syndrome.

To date, there is no known cause of ASD. There are scientists suggested that mutations or rare gene changes are associated with ASD, over the past few years. Rarely, these conditions can cause autism by themselves. However, ASD is more commonly caused by a conjunction of autism risk genes and environmental factors that may influenced the early brain development.

On the other hand, there are presence of non-genetic factors that can elevate an individual's risk such as events before and during birth. These comprise gestational diseases, advanced parental age during time of conception and certain labour and delivery complications, especially in circumstances that may cause baby's brain oxygen deprivation. These conditions are not sufficiently to cause ASD by themselves. In contrast, the risk can be increased moderately if these non-genetic conditions present in addition with the genetic risk factors.

In addition, there are debates about linkage of vaccination and ASD in which some people have the belief that vaccines provided to children may causes ASD. Therefore, there are several studies that involved the evaluation of vaccine ingredients and the amount of antigen in the vaccines received among the autistic and non-autistic children. However, these studies have shown to overturn the belief as vaccines does not cause in developing ASD.

Besides, each autistic individual is affected differently. Some of them are able to live independently and some may have learning disabilities which require a lifetime support from specialists. They may also experience some form of sensory sensitivity or under-sensitivity, for instance to sound, touch, taste, smell, lights or colour. Autism is also considered an unseen condition as some may not show obvious characteristics. Hence none of us can always accurately tell whether someone is autistic. Moreover, it is essential to for the public to understand that ASD will not only influence the children, as autistic children can grow up as autistic adult.

In a nutshell, there is a need to achieve an apprehension of ASD among the medical professions, in order to plan a suitable and proper management of the disorder. This research is designed to study the extent of literacy among clinical year medical students towards individual with ASD. There is an importance of the need of them to understand about ASD as they are the doctor-to-be who may encounter autistic patients during their practice. The literacy about ASD can help them to get early diagnosis of ASD and in providing early intervention towards those who are affected. This study may help to improve their awareness and knowledge about ASD.

\section{Incidence and prevalence}

According to studies in Asia, Europe and North America, the average prevalence of individuals diagnosed with ASD are about $1 \%$ of the world population, while study in South Korea reported a prevalence of $2.6 \%$. It should also be noted males show higher risks for having ASD than females. In Malaysia, there is no official registry for the number of children with autism. However, it is estimated that in every 600 children in Malaysia, one out of them is autistic. Recent statistics show that some 47,000 of the people in this country are autistic. This figures are raising by three percent each year (Yayasan Sime Darby, 2014).

\section{Significant of study}

The purpose of the study is to discover the level of knowledge about ASD among the clinical year medical students. Even though early intervention is important, autism is usually diagnosed only when the child reaches school going age in Malaysia. Due to the lack of awareness and knowledge, there may be delay in providing intervention to those affected as this may worsen their condition. Hence, there is a need of raising the understanding and knowledge of medical students about ASD before they start their practice in hospital or clinic settings. 


\section{Objectives}

General Objective:

To assess the literacy of Autism Spectrum Disorder (ASD) among clinical year medical students in Malaysia

Specific Objectives:

1. To identify the beliefs of clinical year medical students regarding ASD

2. To explore the level of knowledge about ASD among clinical year medical students

3. To discover the attitudes of clinical year medical students towards autistic individual

\section{Literature review}

In recent years, the prevalence rates of autism have increased. A California statistics identified a $17.6 \%$ per year increase in the prevalence rates of autism between the birth cohorts of 1990-1992. According to the study of Durand-Zaleski et al., although 95\% respondents recognized the names of each disorder fewer than $70 \%$ could report specific characteristics and only 33\% considered that publically available information was adequate. The study also showed that most public behaviours and attitudes towards different disorders appear to be based on assumptions, sadly, rather than knowledge or evidence. The study highlighted that the stigmatization of public with mental disorders can be changed eventually with certain alterations in knowledge of mental health.

Although research and literacy on ASDs are increasing worldwide, most studies across the world have reported wide variation of awareness among the public on autism. Studies have found that parents of children with autism noticing and then expressing their worries to health professionals, when their children were between the ages of fifteen to nineteen months. In a study done in Karachi, Pakistan, General Practitioners who were lesser than 30 years of age and five or fewer years after acquisition of their medical degrees were found to be more informed and accurate in their understanding of Autism.

Meanwhile in London, studies were done among medical students to assess their level of awareness about childhood autism. Medical students, who are the future healthcare professionals, are responsible for the diagnosis and management of children with autism. It was observed that fourth year medical students were more likely to correctly respond to questions related to diagnostic criteria and core symptoms .The findings suggest that more emphasis should be placed on teaching medical students about childhood autism to enhance early diagnosis and intervention .

Whereas in a study conducted in Karachi, Pakistan to assess the level of awareness among fourth year medical students, it was found that majority of the student could define autism correctly which is deduced to be due to the increment in the exposure of these disorders through relations with peers, television and social medias. Higher mean scores were obtained by public medical students which can be contributed by the accessibility of heterogeneous patients from all socioeconomic classes. The availability and exposure of patients in the public institute give the medical students a possibility to interact with patients from various departments and aggrandize their clinical knowledge.

When it came down to the community, according to a study done in Harbin, China, participants who lived in urban areas and who had contact with ASD cases were more likely to recognize ASD compared to others . Among the participants, 2470 (68.2\%) reported that they would consult a psychotherapist for diagnostic evaluation if they find out that their children cannot speak and make eye contact by two years old.

On the other hand, another study was conducted on the same topic of interest in Alabama, Unites States of America. It appears that recent media attention has successfully raised the level of awareness of the populace. Meanwhile, most of the respondents felt that the government was not spending enough on services for autistic people. Respondents were then asked to rate the level of importance of service areas that represent the need for lifelong necessities and supports to assist individuals and their families. 
Education wise, the public felt that schools should accommodate the facilities needed by students with autism and that the benefits should begin as early in the life of the child as possible. Regarding the arrangement of educational services in inclusive classrooms, the responses were nearly equally divided. This outcome emulates an ongoing debate among special education professionals referring to the right to involve as a full member of the school community and the conceivable need for separation for some forms of comprehensive instructions. In addition to that, our educational system must prepare students with autism and other developmental disabilities to be productive citizens within their communities. As autism is a spectrum disorder, a sequence of career and vocational training, and job opportunities must be made obtainable with the eventual goal being full time ambitious employment.

As a wrap up, in some parts of the world awareness has been raised and attitudes and behaviours towards autism is changing for the betterment of the public. However, studies done worldwide have proven that autism awareness is still in bleak, hence, researches and studies should be done further on the ways to tackle this ignorance among public and show a little more compassion towards autistic people. Schools and employers should make way and special arrangements rather than alienating them instead of accepting them the way they are. Medical students must add on to their knowledge about autism so that in future they would be able to diagnose correctly and provide insights to their future generations. Doctors should provide consultations and better understanding to parents with autistics children or even the public in order to change the negative attitude towards autistic people. Government plays a vital role in that matter and changes are hoped to be seen in the upcoming years.

\section{Methodology}

\section{Study design}

This was a quantitative approach study in which the data was assessed cross-sectional and descriptively. The target population of this study was clinical year medical students from private and public universities. The data was collected through the method of multi-stage sampling which includes cluster and simple random sampling.

\section{Sample population}

The sample size of this study was 210 students. All medical students in Malaysia were encouraged to participate in this study provided that they are currently studying in year 3 and above.

\section{Survey instrument}

A questionnaire was distributed in public and private universities for the purpose of data collection in this study. The answered questionnaire was collected after completion on the spot itself. Before the distribution of the questionnaire to the respective universities, a pre-test was conducted. The pre-test was distributed among 20 clinical year medical students studying in Master skill University College of Health Sciences (MUCH). A reliability test was conducted on the results of the pre-test, which the Cronbach's alpha value obtained was 0.753. This test was analysed by PASW Statistics Student Version 18. The questionnaire was then considered validated.

\section{Questionnaire design}

The components of the questionnaire was adapted and modified from few different sources. The questionnaire consisted of four parts. Part 1 explored the socio-demographic details about the respondents such as the gender, ethnicity, types of institution and education level. Next, Part 2 identified the belief of the respondents about autism which was partly adapted from the study done by Stone. Part 3 was adapted from KCAHW questionnaire created by Bakare et al. to determine the extent of knowledge of the respondents. Last part of the questionnaire, Part 4, assessed the attitudes of the respondents toward autistic individuals. Some item of this part was taken from the study done by Edyvean. 
There were overall of 35 questions in this questionnaire. Part 1 consisted of 4 questions, Part 2 with 7 questions, Part 3 with 19 questions and lastly Part 4 with 5 questions. Part 2 and Part 3 were analysed according to the total scores achieved where the respondents could achieved the maximum score of 7 in Part 2 and 19 in Part 3 or a minimum score of zero in each part.

\section{Data analysis}

The primary data analysis was coded and analysed by PASW Statistics Student Version 18. Descriptive statistics were used to describe the demographic features of the participants and tables, charts, mean and percentages were used to interpret the results.

\section{Ethical consideration}

The protocol was required to be reviewed by Medical Research Ethical Committee (MREC) of MUCH to insure full protection of the rights of study subjects. NMRR (National Malaysian Research Register) registration was carried out after the approval by MREC. Following the acquisition of NMRR registration number, the questionnaires were distributed to the study subjects. To assure the confidentiality of all the information provided, a cover letter was attached with the questionnaire.

\section{Results \& discussion}

Table 1. Socio-demographic of the Clinical Medical Students

\begin{tabular}{|l|l|c|c|}
\hline \multicolumn{2}{|l|}{ Variables } & Frequency (n) & Percentage (\%) \\
\hline \multirow{2}{*}{ Gender } & Male & 70 & 33.3 \\
\cline { 2 - 4 } & Female & 140 & 66.7 \\
\hline Ethnicity & Malay & 45 & 21.4 \\
\cline { 2 - 4 } & Chinese & 70 & 33.3 \\
\cline { 2 - 4 } & Indian & 81 & 38.6 \\
\cline { 2 - 4 } & Others & 14 & 6.7 \\
\hline \multirow{4}{*}{ University } & Public & 31 & 14.8 \\
\cline { 2 - 4 } & Private & 179 & 85.2 \\
\hline \multirow{2}{*}{\begin{tabular}{l} 
Lducation \\
\cline { 2 - 4 }
\end{tabular}} & $3^{\text {rd }}$ Year & 112 & 53.3 \\
\cline { 2 - 4 } & $4^{\text {th }}$ Year & 64 & 30.5 \\
\cline { 2 - 4 } & $5^{\text {th }}$ Year & 34 & 16.2 \\
\hline
\end{tabular}

Data from 210 clinical year medical students in Malaysia was analysed. Table 1 shows the pattern of distribution of socio-demographic variables of the study: gender, ethnicity, type of university and education level. In this study, there were 70 (33.3\%) males and 140 (66.7\%) females. Most of the students were Indians (38.6\%), followed by Chinese (33.3\%), Malays (21.4\%), and others (6.7\%). As shown in the table, there were more students from private universities (85.2\%) compare to the public universities (14.8\%). According to the education level of the respondent, the $3^{\text {rd }}$ year medical students had highest percentage of participation (53.3\%), while the $5^{\text {th }}$ year medical students had the lowest percentage (16.2\%). 
South American Journal of Medicine

Volume 4, Issue 1, 2016

Table 2a.Score Distribution on Belief about Autism

\begin{tabular}{|l|l|l|l|l|}
\hline Scores & Frequency (n) & Percentage (\%) & Total Mean Score & Std. Dev. \\
\hline 0 & 2 & 1.0 & & \\
\cline { 1 - 2 } 1 & 5 & 2.4 & & \\
\hline 2 & 24 & 11.4 & \multirow{3}{*}{3.84} & \multirow{2}{*}{1.36} \\
\hline 3 & 54 & 25.7 & & \\
\cline { 1 - 2 } 4 & 63 & 30.0 & & \\
\hline 5 & 38 & 18.1 & & \\
\hline 6 & 18 & 8.6 & & \\
\hline 7 & 6 & 2.9 & & \\
\hline
\end{tabular}

*Std. Dev.: Standard deviation

Table 3 portrays the numbers and percentages of the scores that the clinical year medical students have achieved on the questionnaire. The total scores ranged from 0 to 7 . An achievement of maximum score of was required to indicate the students to have an accurate belief about autism. However, there were only 6 (2.9\%) out of 210 students who obtained the maximum score. The total mean score on belief about autism was $3.84 \pm 1.36$ out of 7 . The scores are slightly deviated away from the total mean scores by standard deviation of 1.36 . These findings suggest that most of the clinical year medical students had misconception about ASD. This indicates that majority of the population is not familiar with the basic facts about autism as there is lack of exposure on autism and hence lead to limited attention on autism in Malaysia.

Table 2b. Number and Percentage of Correct Responses for Each Item on Belief about Autism

\begin{tabular}{|l|l|l|}
\hline \multirow{2}{*}{ Item } & \multicolumn{2}{|l|}{ Correct Responses } \\
\cline { 2 - 3 } & Frequency (n) & Percentage (\%) \\
\hline 1. Autism is an emotional disorder. (D) & 119 & 56.7 \\
\hline $\begin{array}{l}\text { 2. Vaccines can cause autism in children. } \\
\text { (D) }\end{array}$ & 141 & 67.1 \\
\hline $\begin{array}{l}\text { 3. Males is more frequently diagnosed with } \\
\text { autism compare to females. (A) }\end{array}$ & 125 & 59.5 \\
\hline $\begin{array}{l}\text { 4. Children with autism can grow up to live } \\
\text { independently. (A) }\end{array}$ & 126 & 60.0 \\
\hline $\begin{array}{l}\text { 5. Autism can be cured. (D) } \\
\text { 6. With the proper treatment, most children } \\
\text { with autism will eventually outgrow it. (D) }\end{array}$ & 30 & 37.1 \\
\hline $\begin{array}{l}\text { 7. It is essential for autistic children to } \\
\text { receive special education services. (A) }\end{array}$ & 188 & 14.3 \\
\hline
\end{tabular}

*D: Disagree

*A: Agree

Based on Table 2b, we can observed that majority of the students (89.5\%) were able to answer item 7 ("It is essential for autistic children to receive special education services.") correctly. This finding is in agreement with a study assessing the autism awareness based on the view of campus community by Leigh Ann Tipton et al. In this study, minority of the 
students (14.3\%) were able to response correctly that with proper treatment, most children with autism actually will not eventually outgrow it (Item 6). This is similar to results reported by Stone et al. On the other hand, most of the students believe that autism can be cured (Item 5), in fact, actually autism are non-curable. Although it is non-curable, interventions could be tailored to autistics which may varies among one another. The percentage of the correct responses for this item is stated to be $37.1 \%$. Meanwhile, in the previous study of Leigh and colleagues shows $58.1 \%$ where we noticed that the percentage was approximately decreased to half in our study. The responses for the other items $(1,2,3, \& 4)$ support the findings of their study.

Table 3a. Score Distribution on Knowledge about ASD

\begin{tabular}{|c|c|c|c|c|}
\hline Scores & Frequency (n) & Percentage (\%) & Total Mean Score & Std. Dev. \\
\hline 0 & 1 & 0.5 & \multirow{20}{*}{12.93} & \multirow{20}{*}{3.56} \\
\hline 1 & 2 & 1.0 & & \\
\hline 2 & 1 & 0.5 & & \\
\hline 3 & 2 & 1.0 & & \\
\hline 4 & 2 & 1.0 & & \\
\hline 5 & 2 & 1.0 & & \\
\hline 6 & 1 & 0.5 & & \\
\hline 7 & 2 & 1.0 & & \\
\hline 8 & 8 & 3.8 & & \\
\hline 9 & 8 & 3.8 & & \\
\hline 10 & 10 & 4.8 & & \\
\hline 11 & 20 & 9.5 & & \\
\hline 12 & 26 & 12.4 & & \\
\hline 13 & 20 & 9.5 & & \\
\hline 14 & 31 & 14.8 & & \\
\hline 15 & 26 & 12.4 & & \\
\hline 16 & 21 & 10.0 & & \\
\hline 17 & 10 & 4.8 & & \\
\hline 18 & 14 & 6.7 & & \\
\hline 19 & 3 & 1.4 & & \\
\hline
\end{tabular}

Table 3a depicts the pattern of distribution of the scores on the knowledge about ASD. A total score of 19 was the maximum score possible on questionnaire where the knowledge about ASD is assessed. Besides, the knowledge about ASD is considered to be adequate if only the maximum score is achieved. Therefore, in this study, it was reported that only 3 (1.4\%) students out of 210 considered to have adequate knowledge. The standard deviation of 3.56 indicates that the scores of the students were slightly polarized. The total mean score on the knowledge was $12.93 \pm 3.56$ out of 19 . This value is found out to be closely similar with a study assessing the knowledge about childhood autism among paediatric and psychiatric nurses in Ebonyi state, Nigeria by Monday N Igwe et al. which observed a total mean score of $12.56 \pm 3.23$ out of a total of 19 possible. According to their studies, the total mean score of $12.93 \pm 3.56$ out of 19 is low and is a reflection of deficits in knowledge about autism.

On the basis of the total mean score of $12.93 \pm 3.56$, data was dichotomized into above average and below average. Thus, 85 (40.8\%) students had knowledge below the mean score and 125 (59.2\%) students had higher scores.

Furthermore, the score of 14 out 19 had the highest number of achievers which is 31 (14.8\%). The median score for total knowledge score was 10. It is interesting to note that 171 (81.5\%) students which considered as the majority of the population scored higher than the median score.

However, these findings suggest that the knowledge of the students regarding ASD was considered low according to Monday N Igwe et al. as a maximum score of 19 should be 
South American Journal of Medicine

Volume 4, Issue 1, 2016

achieved in order to be claimed to have adequate knowledge. The strict scoring system can be due to the increasing incidence and prevalence of autism and also the increasing of childhood neuro-developmental disorders being recognized with high demands for earlier diagnosis and intervention.

Table 3b. Scores Distribution on Knowledge about ASD According to Each Domain

\begin{tabular}{|c|c|c|c|}
\hline Domain & Scores & Frequency (n) & Percentage (\%) \\
\hline \multirow{9}{*}{$\begin{array}{l}\text { Domain 1: Impairment in Social } \\
\text { Interaction }\end{array}$} & 0 & 6 & 2.9 \\
\hline & 1 & 6 & 2.9 \\
\hline & 2 & 2 & 1.0 \\
\hline & 3 & 12 & 5.7 \\
\hline & 4 & 16 & 7.6 \\
\hline & 5 & 36 & 17.1 \\
\hline & 6 & 36 & 17.1 \\
\hline & 7 & 44 & 21.0 \\
\hline & 8 & 52 & 24.8 \\
\hline \multirow{2}{*}{$\begin{array}{l}\text { Domain 2: Impairment in } \\
\text { Communication and Language } \\
\text { Development }\end{array}$} & 0 & 66 & 31.4 \\
\hline & 1 & 144 & 68.6 \\
\hline \multirow{5}{*}{$\begin{array}{l}\text { Domain 3: Obsession and } \\
\text { Compulsive Pattern of Behaviour }\end{array}$} & 0 & 16 & 7.6 \\
\hline & 1 & 19 & 9.0 \\
\hline & 2 & 43 & 20.5 \\
\hline & 3 & 68 & 32.4 \\
\hline & 4 & 64 & 30.5 \\
\hline \multirow{7}{*}{$\begin{array}{l}\text { Domain 4: Co-morbid Conditions } \\
\text { and Onset of Autism }\end{array}$} & 0 & 3 & 1.4 \\
\hline & 1 & 4 & 1.9 \\
\hline & 2 & 21 & 10.0 \\
\hline & 3 & 64 & 30.5 \\
\hline & 4 & 62 & 29.5 \\
\hline & 5 & 46 & 21.9 \\
\hline & 6 & 10 & 4.8 \\
\hline
\end{tabular}

Table 3b displays the distribution of the scores based on domains. A maximum score in each domain should be achieved in order to indicate the adequacy of knowledge about ASD (Domain $1=8$, Domain $2=1$, Domain $3=4$ \& Domain $4=6$ ). It is observed that in Domain 1 , there were only $52(24.8 \%)$ students, Domain 2 with $144(68.6 \%)$ students, the next is Domain 3 with 64 (30.5\%) and lastly in Domain 4 with only 10 (4.8\%) students who were able to achieve a maximum score in each respective domain. Therefore, we could suggest that students were more knowledgeable in Domain 2 which is related to impairment in communication and language development. Meanwhile, the least knowledgeable domain was Domain 4 which is related to co-morbid conditions and onset of autism.

Table 4. Numbers and Percentages of the Positive Responses on Attitudes towards Autistic Individual

\begin{tabular}{|l|l|l|}
\hline \multirow{2}{*}{\multicolumn{1}{|c|}{ Item }} & \multicolumn{2}{c|}{ Positive Responses } \\
\cline { 2 - 3 } & Frequency (n) & Percentage (\%) \\
\hline $\begin{array}{l}\text { 1. Are you willing to move next door to an } \\
\text { individual with ASD? }\end{array}$ & 189 & 90.0 \\
\hline $\begin{array}{l}\text { 2. If an autistic person sits next to you in the bus, } \\
\text { will you change your seat? }\end{array}$ & 200 & 95.2 \\
\hline $\begin{array}{l}\text { 3. Do you see autistic individuals as normal } \\
\text { individuals? }\end{array}$ & 180 & 85.7 \\
\hline
\end{tabular}




\begin{tabular}{|l|l|l|}
\hline $\begin{array}{l}\text { 4. Do you feel frightened if an autistic person shares } \\
\text { the same classroom with you? }\end{array}$ & 201 & 95.7 \\
\hline $\begin{array}{l}\text { 5. Do you think autism is the fault of the person who } \\
\text { has it? }\end{array}$ & 204 & 97.1 \\
\hline
\end{tabular}

In Table 4, it can be noticed that on item 5 ("Do you thinks autism is not the fault of the person who has it"), the positive responses was the highest percentage (97.1\%) when compare to the other items. When the students are being asked whether they see autistic individuals as normal individuals, $85.7 \%$ of them see autistic individual as normal individuals. This item show the least number of positive responses when compare to the others which achieved $90 \%$ or higher positive responses. However, the findings in this study depicts that there was lack of appropriate attitude of the clinical year medical students, unless a maximum percentage of $100 \%$ is achieved in each item. This can proved that there is still presence of stigmatization or discrimination. Low level of knowledge about ASD can lead to stigmatization or discrimination towards autistic individuals as well as their families in the society. They may experience avoidance and negative reaction from the public.

\section{Socio-demographic related to literacy of ASD}

The significance difference between the socio-demographic variables with the belief, knowledge and attitudes towards ASD individual were examined. An independent samples ttest was conducted to examine whether there was a significant difference between the variables of gender (Male or Female) and type of institution (Public or Private) in relation to their beliefs and knowledge about ASD. The test revealed that there are no significant differences between those gender with the total mean score related to beliefs $(\mathrm{t}=0.00, \mathrm{df}=$ 208, $\mathrm{p}=1.00)$ and knowledge $(\mathrm{t}=0.16, \mathrm{df}=208, \mathrm{p}=0.870)$.

Next, there was insignificant differences found in between the type of institution and the total mean score related to belief about ASD. On the other hand, the type of institution and the total mean score related to knowledge about ASD revealed a statistically significant difference $(\mathrm{t}=1.99, \mathrm{df}=208, \mathrm{p}=0.048)$. Public students (Mean $\pm \mathrm{SD}=14.10 \pm 3.00)$ reported significantly higher levels of knowledge about ASD than private students (Mean \pm $\mathrm{SD}=12.73 \pm 3.62$ ). This finding is supported by the previous studies of Farah Shaukat et al. which assessed the knowledge about childhood autism among medical students from private and public universities in Karachi.

In addition, the statistical significant difference among the students with different ethnicity and education level relation to their beliefs and knowledge was examined by a one-way ANOVA. The comparisons of the ethnicity of the students with the total mean score regarding the belief and knowledge revealed no significant relationship.

In contrast, total belief mean score by education showed a significant relationship as an ANOVA test between means yielded $\mathrm{F}=9.252$ at $\mathrm{p}=0.000$, for $\mathrm{p}<0.05$. In conjunction with that, a Games-Howell post hoc test was conducted for the comparisons between different education level groups. The results indicated that $4^{\text {th }}$ year medical students had more accurate beliefs about ASD in comparison with $3^{\text {rd }}$ year students (Mean difference $=-0.47$ at $\mathrm{p}=$ 0.043 ), and finally, $5^{\text {th }}$ year students had more accurate beliefs about ASD in comparison with $3^{\text {rd }}$ year students (Mean difference $=-1.06$ at $\mathrm{p}=0.001$ ).

In relation to the differences between the students' knowledge about ASD with respect to their education level, differences in mean scores were found. $3^{\text {rd }}$ year medical students had a mean score \pm standard deviation $=12.36 \pm 3.37,4^{\text {th }}$ year students had a mean score \pm standard deviation $=13.19 \pm 4.11$ and $5^{\text {th }}$ year students had a mean score \pm standard deviation $=14.32$ \pm 2.59 . An ANOVA test mean yielded $(\mathrm{F}=4.349$ at $\mathrm{p}=0.014$ for $\mathrm{p}<0.05$. These results revealed a significant difference between the mean of knowledge about ASD with students' education level. In addition, a Games-Howell post hoc test was conducted for the comparisons between these two variables. Finding shows that $5^{\text {th }}$ year medical students had 
South American Journal of Medicine

Volume 4, Issue 1, 2016

higher level of knowledge regarding ASD compared to $3^{\text {rd }}$ year students (Mean difference $=$ 1.97 at $\mathrm{p}=0.002$ ).

Moreover, the association of the socio-demographic variables with the attitudes were examined by Chi-square tests. We have found out that there was insignificant association found between the gender, ethnicity and types of institution with the attitudes of the students towards autistic person. But, regarding the education levels and the attitudes were found out to have a significant relationship on the item of "Do you feel frightened if an autistic person shares the same classroom with you?" $\left({ }^{2}=10.06, p=0.007\right)$ and "Do you think autism is the fault of the person who has it?" $\left({ }^{2}=14.67, \mathrm{p}=0.001\right)$. The other items show no significant differences.

\section{Conclusion}

Our data described that $97.1 \%$ of the students have misconception about ASD and only $14.3 \%$ aware that with proper treatment, only minority of the children with autism can outgrow it. $89.5 \%$ of the students agree with the fact that it is essential for autistic children to receive special education services.

Next, only 3 (1.4\%) of 210 students reported to have adequate knowledge regarding ASD. In overall, the students were most knowledgeable about the impairment in communication and language. The students were least aware of the co-morbid conditions and onset of autism.

Besides, our study portrays the lack of appropriate attitudes of the students. For example, as from what we observed, there are $85.7 \%$ of the students who see the autistic individual as normal individual, mean to say that there are still presence of $14.3 \%$ of the students who see them as abnormal. Thus, this shows that there are still certain level of stigmatization or discrimination which occurred, unless the maximum percentage (100\%) of positive responses are achieved by all the participants.

The belief, knowledge and attitudes are expected to be high and good among the medical students as they have higher opportunity to learn more about ASD as compare to the public. They should be more understanding towards the autistics because they will soon become the future healers to the public regardless of their specialization. However, we still see a need of improvement about ASD in terms of belief, knowledge and attitudes among the clinical year medical students in Malaysia.

Belief and attitudes toward autistics can be improved in such a way that medical students would be exemplary to the public on the way autistics should be treated. Ignorance is due to lack of knowledge thus, medical students should be equipped to educate the public regarding autism to eliminate the existing ignorance that can be seen in the public's attitude towards autism.

As what we have learned, autistics should not be isolated but must be given special attention instead as they require sophisticated methods of teaching. This would enable them the opportunity to enhance their talents and skills. Teaching is not only specific for teachers but to even those who come across an autistic child albeit in their family or even friends. It takes time and patience to identify what the child is really keen on and to explore more about it with the child. Self-esteem can be boosted by letting the autistic child to do what he or she seems to be good at. This would open up an array of opportunities for the child to venture on in the future.

According to the recommendations that we have listed previously, efforts should be taken for the betterment of the current situation. Instead of relying fully on the government, nongovernment organizations (NGOs) can give a hand in raising awareness among the public and any special target group of their choice. By doing so, they will be helping our nation rise in an aspect that we all would have least expected; the mental health field. It is a known fact that ASD comes under Psychiatry, thus knowledge on this field would be better and it would gradually reduce a specific taboo which is all Psychiatry patients should be sent to an asylum and treated as people who have gone insane. 
With that said, we hope to see changes among medical students and the citizens of Malaysia regarding ASD gradually. Patience and teamwork is what needed to achieve our goals and together we shall rise to gain some knowledge, educate and treat autistics like how they are supposed to be treated.

To conclude our research, lack of literacy of ASD was obvious among clinical year medical students according to our data.

\section{Recommendations}

There are obvious loopholes that could be rectified using certain methods that can be applied and carried out either in the short term or in the long run. First of all, medical students should take the initiative and have self-directed learning sessions about autism to equip themselves the knowledge that is required for them to identify and diagnose autism in their career. It has come to our attention that the criteria to diagnose an autistic child, which is the stepping stone to the management of such as cases are not being taught to medical students. Not forgetting the fact that the curriculum is standardized worldwide thus the probability to alter the curriculum seems low as it requires more time and work. However, students ought to be enthusiastic and build the curiosity to learn more about autism.

Moving on, various articles should be available for medical students in online continuing medical education (CME) so that when they read the articles and attempt the questions provided, it will boost their understanding towards autism and the ways to manage it. Health care professionals from various medical institutions as well as health care settings should organise CMEs and enable medical students to attend and gain more knowledge regarding autism. Psychiatrist could give talks and explain thoroughly as autism is a spectrum disorder and one autistic child always varies from the other. This could greatly benefit medical students in the future.

Furthermore, Ministry of Health should realise the current situation which is lack of knowledge and understanding of autism among medical students and they should organise campaigns, camps or workshops in which medical students would gain more knowledge and maybe come across autistic children and learn the ways to handle and manage them. Exposure to a certain matter is so vital in understanding of its kind and same goes to this issue that we are trying to tackle now. Visits to care homes that shelter autistics and special education schools should be organised for medical students in order for them mingle around the children and this matter would be alien to them no more.

Besides that, non-governmental organizations (NGOs) should organize events for medical students in which activities would be carried out which would help the students to learn the more about the ways to diagnose and autistic child. Field trips to KIWANIS Home which is the special care home for the autistics can also be conducted so that the exposure could aid in medical students' learning and understanding of autism.

In a nutshell, there are so many ways to curb the lack of literacy of autism among medical students. All parties need to come hand-in-hand in order to produce a quality bunch of future doctors who would be better equipped with adequate knowledge and skills to treat and manage any type of patients.

\section{Acknowledgements}

This study was made complete by the close monitoring of our Research Advisor, Dr. Roy Rillera Marzo, without whose advice and suggestions this research would not have been made possible. We would also like to express our utmost gratitude to all medical students who responded to our study for their cooperation. 
South American Journal of Medicine

Volume 4, Issue 1, 2016

\section{References}

[1.] Arif, M. M., Ayesha Niazy, Bilal Hassan, \& Farah Ahmed. (2013). Awareness of Autism in Primary School Teachers. (M. V. Pletnikov, Ed.) Autism Research and Treatment, 1-5.

[2.] Autism Speaks Inc. (n.d.). What is Autism? Retrieved from Autism Speaks: https://www.autismspeaks.org/what-autism

[3.] Autism Speaks Organization. (n.d.). What is Autism? Retrieved from Autism Speaks: https://www.autismspeaks.org/what-autism

[4.] Bakare, M. O., M. F. TundeAyinmode, A. O. Adewuya, M. A. BelloMojeed, S. Sale, B. O. James, . . . A. O. Orovwigho. (2015). Recognition of Autism Spectrum Disorder (ASD) symptoms and knowledge about some other aspects of ASD among final year medical students in Nigeria, SubSaharan Africa. BMC Research Notes, 1-8.

[5.] Bakare, M. O., Peter O Ebigbo, Ahamefule O Agomoh, \& Nkem C Menkiti. (2008). Knowledge about childhood autism among health workers (KCAHW) questionnaire: description, reliability and internal consistency. Clinical Practice and Epidemiology in Mental Health, 1-8.

[6.] BERNAMA. (2014, March 28). With support, autistic children can move on. Retrieved from The Malaysian Times: http://www.themalaysiantimes.com.my/with-support-autistic-children-can-move-on/

[7.] Broder-Fingert, S., Christine F. Ferrone, Ann Giauque, \& Susan L. Connors. (2014). Residents' Knowledge and Comfort With Caring for Children With Autism Spectrum Disorder. Clinical Pediatrics, 1390-1392.

[8.] Campbell, D. J., David N. Ellis, Abigail Baxter, \& Keith Ni. (2007). Alabama Autism Awareness Assessment.

[9.] Campbell, L. (2008). An Assessment of Autism Knowledge in the Medical Field. 1-90.

[10.] Centers for Disease Control and Prevention. (2015, August 12). Facts About ASD. Retrieved from Centers for Disease Control and Prevention: http://www.cdc.gov/ncbddd/autism/facts.html

[11.] Croen, A., Grether, J.K. , Hoogstrate, J. , \& Selvin, S. (2002). Descriptive Epidemiology of autism in California population: Who is at risk?. Journal of Autism and Developmental Disorders, 32, $217-224$

[12.] Daley TC, S. M. (2002). Diagnostic Conceptualization of Autism among Indian Psychiatrist, Psychologist and Pediatrician. J Autism Developmental Disorder, 13-23.

[13.] Daugherty, C. (2012). The Knowledge and Awareness of Autism Spectrum Disorders within the Hispanic Community. 1-17.

[14.] DeStefano, F., Cristofer S. Price, \& Eric S. Weintraub. (2013). Increasing Exposure to AntibodyStimulating Proteins and Polysaccharides in Vaccines Is Not Associated with Risk of Autism. The Journal of Paediatrics, 561-567. Retrieved from Vaccines Do Not Cause Autism: http://www.jpeds.com/article/S0022-3476(13)00144-3/pdf?ext=.pdf

[15.] DeVilbiss, E. A., \& Brian K. Lee. (2014). Brief Report: Trends in U.S. National Autism Awareness from 2004 to 2014: The Impact of National Autism Awareness Month. Journal of Autism \& Developmental Disorders, 3271-3273.

[16.] Diagnostic and Statistical Manual of Mental Disorder Fifth Edition DSM-5. (2013). Washington, DC: American Psychiatric Publishing.

[17.] Dillenburger, K., Julie-Ann Jordan, \& Lyn McKerr. (2013). Autism Spectrum Disorder:Public awareness and attitudes. Research Update.

[18.] Dillenburger, K., Lynne McKerr, \& Julie-Ann Jordan. (2015). Children and young people's awareness, knowledge, and attitudes towards autism in Northern Ireland. Research Update.

[19.] Durand-Zaleski, Jan Scott, Frédéric Rouillon, \& Marion Leboyer. (2012). A first national survey of knowledge, attitudes and behaviours towards schizophrenia, bipolar disorders and autism in France. BMC Psychiatry 2012, 8.

[20.] Edyvean, C. (n.d.). Attitudes Toward Autism: Reducing Discrimination with Contact. 1-22.

[21.] Haimour, A. I., \& Yahia F. Obaidat. (2013). School Teachers' Knowledge about Autism in Saudi Arabia. World Journal of Education, 45-56.

[22.] Hansen, L. K. (2015). Development and Validation of a Survey of Knowledge of Autism Spectrum Disorder. 1-75.

[23.] Harrison, A. J., B. L. Cochran, \& K. K. Blane. (2015). ASD Knowledge and Stigmas in Tanzania. 
[24.] Heidgerken, A. D., Gary Geffken, Avani Modi, \& Laura Frakey. (2005). A Survey of Autism Knowledge in a Health Care Setting. Journal of Autism and Developmental Disorders, 323-330.

[25.] Igwe, M. N., Muideen O Bakare, Anthony C Ahanotu, Justin U Achor, \& Chinonyerem Igwe. (2011). Assessment of knowledge about childhood autism among paediatric and psychiatric nurses in Ebonyi state, Nigeria. Child and Adolescent Psychiatry and Mental Health, 1-8.

[26.] Imran, N., Mansoor R Chaudry, Muhammad W Azeem, Muhammad R Bhatti, Zaidan I Choudhary, \& Mohsin A Cheema. (2011). A survey of Autism knowledge and attitudes among the healthcare professionals in Lahore, Pakistan. BMC Pediatrics, 1-6.

[27.] K., S. (2001). Research in brief: what do medical students know about autism? Autism, 127-133.

[28.] Khemlani, A. (2015, December 14). Autism Awareness. Spotlight Health Care, p. 17 \& 25.

[29.] Laura Simmons. (2008). Think differently-act positively. London: The National Autistic Society.

[30.] Ministry of Education. (2012, September). The Ministry of Education Malaysia Preliminary Report of National Education Blueprint 2013-2025. Retrieved from Kementerian Pendidikan Malaysia: http://www.moe.gov.my/userfiles/file/PPP/Preliminary-Blueprint-Eng.pdf

[31.] Ministry of Health. (2014). Management Of Autism Spectrum Disorder In Children and Adolescents. Putrajaya: Malaysia Health Technology Assessment Section (MaHTAS).

[32.] Nair, R. (2015). Challenges, Strategies and Success Gained By a Teacher in Teaching Autism Students in a Private Centre. International Journal of Social Science and Humanities Research, 419425.

[33.] National Institute of Mental Health. (n.d.). Autism Spectrum Disorder. Retrieved from National Institute of Mental Health: http://www.nimh.nih.gov/health/topics/autism-spectrum-disordersasd/index.shtml

[34.] O'Leary, M. B. (2014, February 27). Study reveals why autism is more common in males. Retrieved from ELSEVIER: https://www.elsevier.com/connect/study-reveals-why-autism-is-morecommon-in-males

[35.] Pipkin, L. M. (2011). Physician assistants' knowledge and attitudes regarding Autism. 1-43.

[36.] Rahbar MH, I. K. (2011). Knowledge and attitudes of general practitioners regarding Autism in Karachi, Pakistan. Journal of Autism and Developmental Disorder, 465-474.

[37.] Rhoades, R. A., Angela Scarpa, \& Brenda Salley. (2007). The importance of physician knowledge of autism spectrum disorder: results of a parent survey. BMC Pediatrics, 7-37.

[38.] See, C. M. (2012). The Use of Music and Movement Therapy to Modify Behaviour of Children with Autism. 1103-1116.

[39.] Shaukat, F., Fatima, A., Zehra, N., Hussein, M. A., \& Ismail, O. (2014). Assessment of knowledge about childhood autism among medical students from private and public universities in Karachi. Journal of the Pakistan Medical Association, 1331-1334.

[40.] Small, S. H. (2012). Autism Spectrum Disorders (ASD): Knowledge, Training, Roles and Responsibilities of School Psychologists. 1-220.

[41.] Stone, W. (1987). Cross-disciplinary perspectives on autism. Journal of Pediatric, 615-630.

[42.] Suhaily, b., \& Siti Syuhada, b. (2014). A PRELIMINARY STUDY: AWARENESS, KNOWLEDGE AND ATTITUDE OF PEOPLE TOWARDS CHILDREN WITH AUTISM. Proceeding of the Social Sciences Research ICSSR 2014, 322-332.

[43.] Surmen, A., Seyhan Hidiroglu, Hamide Hande Usta, Muhammed Awiwi, Ahmet Saki Oguz, Melda Karavus, \& Ahmet Karavus. (2015). A study exploring knowledge, attitudes and behaviours towards autism among adults applying to a Family Health Center in Istanbul. North Clin Istanbul, 1318.

[44.] The National Autism Society of Malaysia. (n.d.). What Is Autism? Retrieved from NASOM The National Autism Society of Malaysia: http://www.perkobp.org/Image/What\%20is\%20Autism1.pdf

[45.] Tipton, L. A., \& Jan Blacher. (2014). Brief Report: Autism Awareness: Views from a Campus Community. Journal of Autism \& Developmental Disorders, 477-483.

[46.] Wang, J., Zhou, X., Xia, W., Sun, C., Wu, L., \& JianLi. (2011). Autism awareness and attitudes towards treatment in caregivers of children aged 3-6 years in Harbin, China. Social Psychiatry \& Psychiatric Epidemiology, 1301-1308.

[47.] Yasar, P., \& Kathleen A. Cronin. (2014). Perspectives of College of Education Students in Turkey 
South American Journal of Medicine

Volume 4, Issue 1, 2016

on Autism Spctrum Disorders. INTERNATIONAL JOURNAL OF SPECIAL EDUCATION, 1-15.

[48.] Yayasan Sime Darby. (2014, April 30). Yayasan Sime Darby Wraps Up Autism Awareness Month with Grant to Assist Autistic Children from Poor Families. Retrieved from Yayasan Sime Darby: http://www.yayasansimedarby.com/1405210849\%C2\%BBYayasan_Sime_Darby_Wraps_Up_Autism_ Awareness_Month_with_Grant_to_Assist_Autistic_Children_from_Poor_Families.aspx

[49.] York, A., N. von Fraunhofer, J. Turk, \& P. Sedgwick. (1999). Fragile-X syndrome, Down's syndrome and autism: awareness and knowledge amongst special educators. Journal of Intellectual Disability Research, 314-324.

[50.] YS, K., BL, L., YJ, K., E, F., E, L., \& EC, L. (2011). Prevalence of autism spectrum disorders in a total population sample. 